\title{
A comparative analysis of demographic and aetiological features in young and old patients of buccal mucosa cancer
}

\author{
Kalaivani A.K. ${ }^{1}$, Padma R. ${ }^{2}$, Bhoopathy P. ${ }^{3}$, Sundaresan S. ${ }^{4}$, Valluru V. ${ }^{5}$ \\ ${ }^{1}$ Dr. Kalaivani Amitkumar, Department of Pathology, ${ }^{2}$ Dr. Ramasamy Padma, Senior Research Fellow, Department of \\ Neurosurgery, NIMHANS, Bangalore, ${ }^{3}$ Dr. Prabhu Bhoopathy, Department of Medical Research, ${ }^{4}$ Dr. Sivapatham \\ Sundaresan, Department of Medical Research, ${ }^{5}$ Dr. Vaishali Valluru, Senior Research Fellow, Department of \\ Neurosurgery, NIMHANS, Bangalore; ${ }^{1,3,4}$ authors are affiliated with SRM Medical College Hospital and Research \\ Centre, SRM Institute of Science and Technology, Kattankulathur, Chennai, India.
}

Corresponding Author: Dr. Padma Ramasamy, Senior Research Fellow, Department of Neurosurgery, NIMHANS, Bangalore, E-Mail: drpadmaramphd@gmail.com,drkalaivani1980@gmail.com

\begin{abstract}
Background: Oral squamous cell carcinoma (OSCC) most commonly occurs in the middle-aged and older individuals. It is believed thatrole of aetiologyisdifferent in young and old patients. Objective: This study was conducted to analyse the comparisonof demographic and aetiological difference in young and old patients of buccal mucosa cancer. Materials and Methods: In this retrospective study, demographicand aetiological details were retrieved form medical records between Mar. 2013 and Jan. 2016. Results: The patients were grouped as younger ( $<40$ years) and elder (aged 40 years and above). Of 198 patients, higherincidence was observed in older patients. Both younger and older groups showed male predominance (male: female ratio was 4:1 and 3.7:1 in younger and older groups, respectively). Conclusion: The present study proved that young ( $<40 \mathrm{yrs}$ ) adults with OSCC showed aggressive course compared with elders ( $\geq 40$ yrs). The aggressiveness of disease may be due to the presence ofrisk habits. However, further studies need to find the hidden risk factors for lower survival.
\end{abstract}

Keywords: Age group, Aetiology, Risk factor, Buccal mucosa cancer

\section{Introduction}

Oral squamous cell carcinoma (OSCC) is the leading cause of morbidity and mortality across the world [1]. Several Indian studies reported that the most frequent incidence of intra oral-site was buccal mucosa cancerwhich accounts for $34 \%-40.2 \%$ [2,3]. The incidence of oral squamous cell carcinomas varies in different parts of the world and this difference is largely attributed to the exposureto risk factors specific to the area. In India, oral cancer ranks the first among male and the third amongfemale population which is related to the use of tobacco chewing [4].

Traditionally, oral cancer is a disease mainly affecting in low income communities, patient aged around sixth decade and among both genders [1]. Changing pattern in the incidence of oral squamous cell carcinoma suggested that younger patients are at risk of developing aggressive pattern of disease. This may reflect differences between carcinogens to which the younger

Manuscript received: $4^{\text {th }}$ April 2019

Reviewed: $14^{\text {th }}$ April 2019

Author Corrected: $20^{\text {th }}$ April 2019
Accepted for Publication: 23 ${ }^{\text {rd }}$ April 2019

patients were exposed and the carcinogens responsible for malignant transformation [5]. Oral cancer in young adult patients under the age of 35 years forms about $2.8 \%$ of all cases of oral cancer at regional cancer centre, Kerala [6]. The clinical and epidemiological profile of young and elder population of oral cancer had been reported that higher prevalence and poor prognosis among young patients were associated with male gender, lower educational level and pain symptomatology [7].

The biological behaviour and poor clinical prognosis of OSCC in younger were related to increased aggressiveness compared to those affecting elderly $[8,9]$. Santos et al suggested that as these risk factors are causing poor prognosis and lower survival rates, studying the relationship of etiological factorsand biological behaviour of tumour in different age group asin young and old patients will be helpful to understand the pathogenesis and development of oral squamous cell carcinoma [7]. 


\section{Materials and Methods}

Study design and participants: The retrospective study was conducted in Arignar anna memorial regional cancer centre, Kanchipuram, Tamilnadu between 2013 and 2016. The clinically diagnosed, total of 198 buccal mucosa carcinoma patients were included the study. Ethical clearance was approved by directorate medical education (DME), Tamilnadu (Ref No.24984 /2013).

Data collection methods: Data collected for analysis included gender, age, marital status, history of tobacco and alcohol abuse. The patients were categorised into two groups: the young group comprised of patients less

\section{Original Research Article}

than 40 years and the older group comprised of patients aged 40 years and above. Details of clinical staging and histopathology details were collected from patients case data sheet from records, histopathology and classification of tumors based on World Health Organisation Classification of Tumor. Pathology and genetics of head and neck tumors. WHO 2005[10]

Statistical Analysis: SPSS package version 16 was used for all statistical analysis. Chi-square test was performed for association of patient's characteristics with age groups. Significance was set at $\mathrm{P}<0.05$.

\section{Results}

A total of 198 patientsof buccal mucosa cancer were identified during the study period between $2013-2016$. Of these, 71 (35.8\%) were young patients (mean age $32.97 \mathrm{yrs,} \mathrm{range} \mathrm{18-39} \mathrm{yrs)} \mathrm{and} \mathrm{the} \mathrm{remaining} 127$ (64.2\%) were older individuals (mean age 65.54 yrs, range $40-88$ yrs).

Well differentiated buccal mucosa cancer was the most common histologic type in both the older (50.7\%) and younger age (48.8\%) groups and followed by moderately differentiated formed $38 \%$ and $32.3 \%$ of the patients in the older and young age groups, respectively. The remaining patients i.e., $11.3 \%$ of young and $18.9 \%$ of old age groups were diagnosed with poorly differentiated squamous cell carcinoma. However, the histology of buccal mucosa cancer in young and old patients $(\mathrm{p}=0.002, \mathrm{p}<0.05)$ showed significant difference (Table 1).

Table 1 shows the association of clinical TNM stage, nodal status and metastasis with different age groups of patients. In this study, high frequency i.e., $80.3 \%$ and $87.4 \%$ of patients were reported with advanced stages (stage III and IV) in young adults and old age groups, respectively whereas the early diagnosis (stage I and stage II) was observed only in $19.7 \%$ and $12.6 \%$ of young and patients. However, the clinical TNM stage showed significant association with age groups of patients $(\mathrm{p}=0.034, \mathrm{p}<0.05)$. The nodal status and metastasis failed to show the significance difference among the age groups.

The treatment modality of patients based on the histopathology and clinical stage of patients. However, the age is an important factor for treatment support. In the study, $42.3 \%$ of young adults and $23.6 \%$ of old patients were undergone surgery and further adjuvant radio and/or chemotherapy whereas others may not fit for the surgery. Further, the study showed the significant difference of age groups $(\mathrm{p}=0.049, \mathrm{p}<0.05)$ among treatment (Table 1$)$.

Demographic information: Table 1 shows the association of subject's demographic and clinical characteristics with two age groups. Gender $(\mathrm{p}=0.201)$ and marital status $(\mathrm{p}=0.939)$ did not show significant difference among age groups. In young age group, most frequently observed etiological factors are tobacco chewing and smoking habitual (39.4\%) followed by pan chewing with tobacco $(28.2 \%)$ and multihabitual $(16.9 \%)$. In old groups, $52 \%$ of patients had multihabitual followed by $24.4 \%$ pan chewing with tobacco and $7.9 \%$ was alcohol and pan without tobacco habits. Thus, a total of $84.5 \%$ of young patients had consumed tobacco in either smokeless or smoking form whereas $76.4 \%$ had consumed tobacco in old age group.Further, the present study proved highly significant difference between the two groups $(\mathrm{p}=0.000)$ by Pearson's Chi-square analysis at $\mathrm{p}<0.05$.

Well differentiated buccal mucosa cancer was the most common histologic type in both the older (50.7\%) and younger age $(48.8 \%)$ groups and followed by moderately differentiated formed $38 \%$ and $32.3 \%$ of the patients in the older and young age groups, respectively. The remaining patients i.e., $11.3 \%$ of young and $18.9 \%$ of old age groups were diagnosed with poorly differentiated squamous cell carcinoma.

However, the histology of buccal mucosa cancer in young and old patients $(\mathrm{p}=0.002, \mathrm{p}<0.05)$ showed significant difference by chi-square analysis (Table 1). 


\section{Original Research Article}

Table 1 shows the clinical TNM stage, nodal and metastasis association with age groups of patients. In the study, high frequency i.e., $80.3 \%$ and $87.4 \%$ of patients were reported with advanced stage (stage III and IV) in young adults and old age groups, respectively whereas the early diagnosis (stage I and stage II) was $19.7 \%$ and $12.6 \%$ of patients. However, the clinical TNM stage showed significant association with age groups of patients $(\mathrm{p}=0.034, \mathrm{p}<0.05)$. The nodal status and metastasis failed to show the significance difference among the age groups.

The treatment strategies are shown based on the histopathology and clinical stage of patients. However, the age is an important factor for treatment support. In the study, $42.3 \%$ of young adults and $23.6 \%$ of old patients undergone surgery and further adjuvant radio and/or chemotherapy whereas others were not fit for the surgery. Further, the study showed the significant difference of age groups $(\mathrm{p}=0.049, \mathrm{p}<0.05)$ among treatment strategies (Table 1$)$.

Table-1: Demographic and clinical characteristics relation with age groups of subjects

\begin{tabular}{|c|c|c|c|c|}
\hline \multicolumn{2}{|c|}{ Characteristics } & \multirow[t]{2}{*}{$\begin{array}{l}<40 \text { yrs } \\
(\mathrm{n}=71)\end{array}$} & \multirow[t]{2}{*}{$\begin{array}{l}\geq 40 \text { yrs } \\
(n=127)\end{array}$} & \multirow[t]{2}{*}{ p-value } \\
\hline \multirow[t]{3}{*}{ Gender } & & & & \\
\hline & Male & $49(69)$ & $76(59.8)$ & \multirow{2}{*}{0.201} \\
\hline & Female & $22(31)$ & $51(40.2)$ & \\
\hline \multicolumn{2}{|c|}{ Marital status } & & & \\
\hline & Married & $44(62)$ & $78(61.4)$ & \multirow{2}{*}{0.939} \\
\hline & Single/divorced/widow & $27(38)$ & $49(38.6)$ & \\
\hline \multicolumn{4}{|l|}{ Habits } & \\
\hline & Alcohol & $1(1.4)$ & $1(0.8)$ & \multirow{8}{*}{$0.000^{*}$} \\
\hline & Betal quid/ arecanut chewing & $3(4.2)$ & $4(3.1)$ & \\
\hline & Pan (Betal leaf/ quid and lime) & $1(1.4)$ & $4(3.1)$ & \\
\hline & Tobacco (smoking and smokeless) & $28(39.4)$ & $8(6.3)$ & \\
\hline & Alcohol and Pan without tobacco & $6(8.5)$ & $10(7.9)$ & \\
\hline & Pan chewing with tobacco & $20(28.2)$ & $31(24.4)$ & \\
\hline & $\begin{array}{l}\text { Multiple factors (Smoking, smokeless tobacco, } \\
\text { areca nut and alcohol) }\end{array}$ & $12(16.9)$ & $66(52)$ & \\
\hline & No habits & 0 & $3(1.5)$ & \\
\hline \multicolumn{2}{|c|}{ Grade of tumor } & & & \\
\hline & Well differentiated & $36(50.7)$ & $62(48.8)$ & \multirow{3}{*}{$0.002 *$} \\
\hline & Moderately differentiated & $27(38)$ & $41(32.3)$ & \\
\hline & poorly differentiated & $8(11.3)$ & $24(18.9)$ & \\
\hline \multicolumn{2}{|c|}{ Clinical stage } & & & \multirow{5}{*}{$0.034 *$} \\
\hline & Stage I & $8(11.2)$ & $5(3.9)$ & \\
\hline & Stage II & $6(8.5)$ & $11(8.7)$ & \\
\hline & Stage III & $8(11.3)$ & $5(3.9)$ & \\
\hline & Stage IV & $49(69)$ & $106(83.5)$ & \\
\hline \multicolumn{2}{|c|}{ Nodal status } & & & \multirow{3}{*}{0.18} \\
\hline & Negative & $12(16.9)$ & $10(7.9)$ & \\
\hline & Positive & $59(83.1)$ & $117(92.1)$ & \\
\hline \multirow[t]{3}{*}{ Metastas } & & & & \\
\hline & Negative & $53(74.6)$ & $88(69.3)$ & \multirow{2}{*}{0.425} \\
\hline & Positive & $18(25.4)$ & $39(30.7)$ & \\
\hline \multicolumn{2}{|c|}{ Treatment strategies } & & & \multirow{5}{*}{$0.049 *$} \\
\hline & Radiotherapy only & $19(26.8)$ & $40(31.5)$ & \\
\hline & Radio and chemotherapy & $22(31)$ & $57(44.9)$ & \\
\hline & Post operative radiotherapy & $12(16.9)$ & $13(10.2)$ & \\
\hline & PORT and chemotherapy & $18(25.4)$ & $17(13.4)$ & \\
\hline
\end{tabular}

*Statistically significant at $\mathrm{p}<0.05$ level by chi-square analysis 


\section{Original Research Article}

\section{Discussion}

Literature reported that oral cancers in young patients show a general trend of an aggressive course and poor survival [5]. A south Indian study reported with high incidence of oral squamous cell carcinoma among patients below 35 years in 2001[6]. In contrary, another ten years retrospective study was conducted in the same region of Kerala during the period between 2004 and 2014 and reported with high incidence of older (>45yrs) oral cancer patients [11].

However, these studies showed that male patients were predominately affected by oral cancer. As per recent reports, the present three years (2013-2016) retrospective study also showed the high frequency of older patients with male predominance in 1.7:1 ratio.

In our study, high frequency $(80.3 \%$ and $87.4 \%)$ of patients were observed with higher stages (stage III and IV) in both young and old age groups, respectively and the lower stages was observed only in less percentage of cases (19.7\% and $12.6 \%)$ of young and old patients.

Sobinalso discussed about relationship of TNM staging with non-anatomic prognostic factors in his study. [12] Though the nodal status and metastasis failed to show the significance difference, clinical TNM stage showed significant association with age groups of patients $(\mathrm{p}=0.034, \mathrm{p}<0.05)$ in our study.

In the recent studies, it was found that there is strong influence of treatment strategies on the prognosis of buccal mucosa carcinoma as other carcinomas, multimodality including adjuvant chemotherapy showed better survival than single therapy treatment groups. [13]

Tobacco is the major risk factor for oral cancer with numerous studies reported defined association with carcinogenic mechanism. Gupta et al., was pointed the increasing incidence of smokeless tobacco and related products in our country[14]. Iypeet al reported in his study that all the patients $(n=42,91 \%)$ used either tobacco or alcohol, with tobacco chewing being the most common in south Indian young adults [15].

Our study also supports previous results and thepresent study shows that all young patients $(<40 \mathrm{yrs})$ had risk habits exposure.

However, the highincidence of buccal mucosa carcinoma reported with over 40 years old seems to be due to a longer exposure of tobacco and/or alcohol than to the habit itself [11].
Study done by Siriwardena showed no significant difference between two groups based on histology grading systems, a significantly higher number of nuclear aberrations was found in younger group and higher number of mitoses and lymph node metastasis were observed in the older group. [16] Fang KH et al conducted study in betel quid chewing prevalent are and analysed histological differentiation of primary oral squamous cell carcinomas and correlated with other prognostic factors and showed that poorly differentiated tumor types of oral squamous cell carcinoma are significantly associated with positive nodal status, extracapsular spread and perineural invasion. [17] Well differentiated buccal mucosa cancer was the most common histologic type in both groups followed by moderately differentiated and the least number group had poorly differentiated squamous cell carcinoma in our study.

However, the histopathology of buccal mucosa cancer in young and old patients $(\mathrm{p}=0.002, \mathrm{p}<0.05)$ showed statistically significant difference.

Iype reported that survival among young patients was almost similar to that in older patients [18]. In contrary, Salianet al., found in his study that 28-year-old male patient with buccal mucosal cancer were associated with quid chewing and showed poorly differentiated oral squamous cell carcinoma in histopathology with presence ofnodal metastasis and also reported that younger individuals follow a more aggressive disease and poor prognosis $[2,19]$.

Our results are very similar with previous reports, in our study also we observed that young age groups showed poor prognosis than old age. The aggressiveness of disease may be due to risk factor of smokeless and smoking tobacco consumption.

\section{Conclusion}

Buccal mucosa cancer mortality and morbidity is very rampant in our country. The findings of our comparative study indicate a high frequency of pan chewing young adultsin our region which may be related to poor prognosis of buccal mucosa carcinoma in these patients.

The present study proved that young $(<40$ yrs) adults with OSCC showed aggressive course compared with elders ( $\geq 40 \mathrm{yrs}$ ) though treated with standard guideline. The aggressiveness of disease may be due to the presence of risk habits such as smokeless and smoking 
tobacco consumption. However, further studies are needed to establish the role of aetiological factors and its different carcinogenic mechanism in young and old age group of patients to find the hidden risk factors for lower survival.

Contribution by different authors- Dr. P. Kalaivani Amitkumar contributed to study designing, literature search and review, histological data generation, manuscript preparation and editing; Padma Ramasamy contributed to conception of the study, performing the experiments and data acquisition; Bhoopathy Prabhu contributed to data and statistical analysis, Sundaresan Sivapatham contributed to enabling study methodology and data analysis, Vaishali Valluru contributed to study designing and review of literature

What this study adds to existing knowledge: The present study adds new insights to existing knowledge, indicating that the impact of risk habits like pan chewing and tobacco smoking present in younger population contributes to aggressiveness of oral squamous cell carcinoma.

This study also shows poor prognosis and aggressive in younger patients compared to older patients.

The present study has analysed more number of cases of oral carcinoma and specimens compared to previous studies done in Kancheepuram district, Tamilnadu.

Acknowledgement: Our team would like to acknowledge and thank Arignar Anna Memorial Cancer Hospital and Research Centre, Kanchipuram permission to conduct the study.

Findings: Nil; Conflict of Interest: None initiated Permission from IRB: Yes

\section{Reference}

1. Scully C, Bagan J. Oral squamous cell carcinoma: overview of current understanding of aetiopathogenesis and clinical implications. Oral Dis. 2009 Sep;15(6):38899. doi: 10.1111/j.1601-0825.2009.01563.x. Epub 2009 Apr 2.

2. Salian V, Dinakar C, Shetty P, Ajila V. Etiological trends in oral squamous cell carcinoma: A retrospective institutional study. Cancer Transl Med 2016;2(2):33-6.

3. Patil PB, Bathi R, Chaudhari S. Prevalence of oral mucosal lesions in dental patients with tobacco smoking, chewing, and mixed habits: A cross-sectional study in South India. J Family Community Med. 2013 May;20 (2):130-5. doi: 10.4103/2230-8229.114777.

\section{Original Research Article}

4. Moyses RA, Lopez RV, Cury PM, Siqueira SA, Curioni OA, Gois Filho JF, et al. Significant differences in demographic, clinical, and pathological features in relation to smoking and alcohol consumption among 1,633 head and neck cancer patients. Clinics (Sao Paulo). 2013 Jun; 68 (6): 738-744. doi: 10.6061/clinics/ $2013(06) 03$

5. Chandra A, Singh A, Sebastian BT, et al. Oral squamous cell carcinomas in age distinct population: a comparison of p53 immunoexpression. J Cancer Res Ther. 2013 Oct-Dec; 9(4): 587-91. doi: 10.4103/09731482. 126452.

6. Iype EM, Pandey M, Mathew A, et al. Oral cancer among patients under the age of 35 years. J Postgrad Med. 2001 Jul-Sep;47(3):171-6.

7. Santos HBP, dos Santos TKG, Paz AR, Cavalcanti YW, Nonaka CFW, Godoy GP, Alves PM. Clinical findings and risk factors to oral squamous cell carcinoma in young patients: A 12-year retrospective analysis. MedOral PatolOral Cir Bucal. 2016; 21 (2): 151-56.

8. Soudry E, Preis M, Hod R, et al. Squamous cell carcinoma of the oral tongue in patients younger than 30 years: clinicopathologic features and outcome. Clin Otolaryngol. 2010 Aug; 35 (4):307-12. doi: 10.1111/j. 1749-4486.2010.02164.x.

9. Troeltzsch M, Knösel T, Eichinger C, et al. Clinicopathologic features of oral squamous cell carcinoma: do they vary in different age groups? J Oral Maxillofac Surg. 2014 Jul;72(7):1291-300. doi: 10.1016 /j. joms. 2014. 01.009. Epub 2014 Jan 23.

10. Barnes L, Eveson JW, Reichart P, Sidransky O, Geneva: World Health Organisation Classification of Tumor. Pathology and genetics of head and neck tumors. WHO 2005: 168-75.

11. Beena VT, Binidree SS, Ayswarya T, PaikkadanI, Padmakumar SK, Sivakumar R. Oral squamous cell carcinoma in patients younger than 40 years: A 10 years retrospective study. Int J Sci Study 2016; 4(4): 150-53.

12. Sobin LH. TNM: evolution and relation to other prognostic factors. SeminSurg Oncol. 2003;21(1):3-7. DOI:10.1002/ssu.10014

13. Padma R, Thilagavathi R, Sundaresan S. Survival outcomes of buccal mucosa carcinoma patients with multimodality therapy: An institutional study. Int $\mathrm{J}$ NutrPharmacol Neurol Dis 2016; 6: 76-80. 
14. Gupta J, Gupta KK, Samadi FM, Kabiraj A. Smokeless tobacco and oral cancer: A review. Ind $\mathrm{J}$ Oral Sci 2012; 3(2): 74-78.

15. Muwonge R, Ramadas K, Sankila R, et al. Role of tobacco smoking, chewing and alcohol drinking in the risk of oral cancer in Trivandrum, India: a nested casecontrol design using incident cancer cases. Oral Oncol. 2008 May;44(5):446-54. Epub 2007 Oct 22.

16. Siriwardena BS, Tilakaratne A, Amaratunga EA, et al. Analysis of histopathological and immunohistochemical differences of oral squamous cell carcinoma in young and old patients in Sri Lanka. J Oral Pathol Med. 2007 Jul;36(6):357-62. DOI:10.1111/j.1600-0714. 2007.00548.x

\section{Original Research Article}

17. Fang KH, Kao HK, Cheng MH, et al. Histological differentiation of primary oral squamous cell carcinomas in an area of betel quid chewing prevalence. Otolaryngol Head Neck Surg. 2009 Dec;141(6):743-9. doi: 10.1016/j.otohns.2009.09.012.

18.Iype EM, Pandey M, Mathew A, et al. Squamous cell cancer of the buccal mucosa in young adults. Br $\mathrm{J}$ Oral Maxillofac Surg. 2004 Jun;42(3):185-9.

19. Chang TS, Chang CM, Ho HC, et al. Impact of young age on the prognosis for oral cancer: a population-based study in Taiwan. PLoS One. 2013 Sep 26; 8 (9):e75855. doi: 10.1371/journal.pone.0075855. eCollection 2013.

\section{How to cite this article?}

Kalaivani A.K, Padma R, Bhoopathy P, Sundaresan S, Valluru V. A comparative analysis of demographic and aetiological features in young and old patients of buccal mucosa cancer. Trop J Path Micro 2019;5(5):325-330. doi: 10.17511/jopm.2019.i05.11. 